\title{
Percurso de estudantes cotistas: ingresso, permanência e oportunidades no ensino superior
}

\author{
Quota students' path: entrance, stay and opportunities in higher education
}

\begin{abstract}
${ }^{1}$ Mariza Aparecida Costa Pena - Universidade Federal de Ouro Preto | Escola de Medicina | Ouro Preto | MG | Brasil. E-mail: mariza.penna@ ufop.edu.br ORCID: https://orcid.org/0000$\underline{0002-1956-8128}$
\end{abstract}
${ }^{2}$ Daniel Abud Seabra Matos - Universidade Federal de Ouro Preto | Instituto de Ciências Humanas e Sociais | Mariana | MG |Brasil. E-mail: dseabram@gmail.com ORCID: http://orcid.org/0000-0001-7955-4302
${ }^{3}$ Rosa Maria da Exaltação Coutrim - Universidade Federal de Ouro Preto | Instituto de Ciências Humanas e Sociais | Mariana | MG |Brasil. E-mail: rosacoutrim@ufop.edu.br ORCID: https://orcid.org/0000-0002-9510-1263
Resumo: Os objetivos foram: investigar o percurso universitário de alunos cotistas após o ingresso nos cursos de graduação presenciais da UFOP; comparar o perfil acadêmico dos estudantes cotistas e da ampla concorrência e investigar oportunidades aproveitadas no percurso universitário pelos alunos. Utilizamos métodos quantitativos: estatística descritiva e testes de comparação de médias. As variáveis utilizadas foram: nível socioeconômico, nota do ENEM, coeficiente geral da UFOP, reprovação, evasão e oportunidades acadêmicas. Participaram 247 alunos (71 cotistas e 176 da ampla concorrência), ingressantes no primeiro semestre de 2013, pertencentes a seis cursos: Medicina, Nutrição, Engenharia Civil, Engenharia de Computação, Direito e Serviço Social. Dentre os principais resultados, destacamos: a maioria dos estudantes cotistas, embora tenha uma nota menor na pontuação do ENEM ao ingressar, tem desempenho acadêmico similar ao dos estudantes da ampla concorrência. Diversos resultados encontrados, de maneira geral, estão nesse mesmo sentido. Por exemplo: na amostra como um todo, ao compararmos a reprovação e a proporção de evasão de estudantes cotistas e de ampla concorrência, não encontramos diferença estatisticamente significativa. A política de cotas tem colaborado para o acesso de uma parcela significativa de estudantes de camadas populares no Ensino Superior, sobretudo nos cursos de maior prestígio.

Palavras-chave: Estudantes cotistas. Políticas de ação afirmativa. Ensino Superior.

Abstract: The goals were to investigate the university quota students' path after joining UFOP's undergraduate courses; compare the academic profile of quota and other students and investigate the seized opportunities in the university path by the students. We used quantitative methods: descriptive statistics and means comparison tests. The variables used were: socioeconomic status, ENEM score, general UFOP coefficient, grade retention, dropout and academic opportunities. 247 students (71 quota students and 176 from the regular competition), enrolled in the first semester of 2013, from six undergraduate courses participated: Medicine, Nutrition, Civil Engineering, Computer Engineering, Law School and Social Work. Among the main results, we highlight: the majority of quota students, despite having a lower entrance ENEM score, has a similar academic achievement to the students of the regular competition. Several results found, in general, are in the same direction. For instance: in the sample as a whole, we did not find a statistically significant difference when comparing the grade retention and dropout proportion of quota and regular competition students. The quota policy has contributed to the access of a significant number of popular class students in Higher Education, especially in the most prestigious courses.

Keywords: Quota students. Affirmative action policies. Higher education.

- Recebido em: 18 de julho de 2018 • Aprovado em: 6 de dezembro de 2019

DOI: http://dx.doi.org/10.1590/S1414-40772020000100003

Este é um artigo publicado em acesso aberto sob uma licença Creative Commons

https://creativecommons.org/licenses/by-nc/4.0/ 


\section{Democratização do Ensino Superior no Brasil e o acesso das camadas populares}

Visando melhorar os índices de escolarização e democratização do Ensino Superior, diferentes políticas públicas vêm contribuindo para o ingresso e a permanência de segmentos sociais historicamente excluídos do ambiente universitário. Dentre as políticas que têm o foco no acesso ao Ensino Superior, pode-se citar, como um dos principais propulsores, o Plano Nacional de Educação (PNE), que tem como finalidade a redução das desigualdades escolares. O PNE é uma lei ordinária, prevista no Art. 214 na Constituição Federal de 1988, que determina diretrizes, metas e estratégias para a política educacional da Educação Básica ao Ensino Superior. A Emenda Constitucional $n^{\circ}$. 59/2009 mudou a condição do PNE, que passou de uma disposição transitória da Lei de Diretrizes e Bases da Educação Nacional (Lei nº. 9.394/1996) para uma exigência constitucional com periodicidade decenal, o que significa que planos plurianuais devem tomá-lo como referência. Entre as estratégias para o cumprimento das metas do PNE, tem-se o aumento das vagas nas Instituições Federais de Ensino Superior e Tecnológico, o oferecimento de um terço das vagas em período noturno, a ampliação dos programas de inclusão e assistência estudantil e o acesso ao Ensino Superior para egressos do sistema público de ensino.

Embora a presença de segmentos dos meios populares nas instituições de Ensino Superior tenha aumentado significativamente, a democratização está longe de se concretizar e, para que se torne de fato uma realidade, não pode se limitar somente ao acesso nesse nível de ensino (SOUZA, 2016). Mas é inegável que os estudantes provenientes dos estratos populares socialmente desfavorecidos lograram uma conquista importante por meio da Lei $\mathrm{n}^{\circ}$. 12.711 (BRASIL, 2012), que tornou obrigatória a reserva de vagas para pessoas oriundas de escolas públicas, com baixa renda, negros e indígenas em todos os cursos ministrados nas IES federais.

Face à importância dessa temática, nosso objetivo geral foi investigar o percurso universitário de estudantes participantes da política de ação afirmativa após o ingresso nos cursos de graduação presenciais da Universidade Federal de Ouro Preto. Os objetivos específicos foram: comparar o perfil acadêmico dos estudantes cotistas e da ampla concorrência e investigar as oportunidades aproveitadas no percurso universitário pelos alunos. 


\section{Ações Afirmativas no Ensino Superior e a Lei no . 12.711/2012}

Em tese, todos podem ter acesso à educação superior, mas, paradoxalmente, esse acesso tem sido, por várias décadas, exclusividade daqueles com condições que lhes proporcionem escola básica particular de excelência ou cursos preparatórios onerados para os exames de seleção para ingresso, especialmente nos cursos de maior prestígio. Diante dessa situação, lutas históricas e importantes movimentos sociais se insurgiram contra o caráter excludente da educação superior. Destacam-se os movimentos sociais negros, que, de forma contundente, conduziram debates e exigiram a implementação de Ações Afirmativas. O termo Ação Afirmativa, segundo Domingues (2005), surgiu nos Estados Unidos, durante o governo de John Kennedy (1961-1963), para nomear um conjunto de políticas públicas e privadas elaboradas com o intuito de combater a discriminação racial. Assim como os Estados Unidos, outros países também adotaram ações voltadas para a promoção de diferentes grupos.

A adoção da Ação Afirmativa no Ensino Superior abrange ações desde o pré-ingresso (cursos preparatórios para o vestibular e isenção de taxa de inscrição), perpassa pelo ingresso (cotas) e acompanha até a diplomação, por meio dos programas de assistência e de permanência estudantis. Nesse contexto, surgem as Ações Afirmativas para ingresso na universidade. A implantação de cotas raciais para acesso de estudantes de escolas públicas no Ensino Superior brasileiro teve como pioneiras a Universidade Estadual do Rio de Janeiro e a Universidade Estadual do Norte Fluminense (2002), em âmbito estadual, e a Universidade de Brasília (2003), no âmbito das instituições federais. Na sequência, as Ações Afirmativas foram implementadas por várias instituições de Ensino Superior no país (MUNANGA, 2008; PAIVA; ALMEIDA, 2010; SOUSA, 2013; PORTES; SILVA, 2011; SANTOS, 2011; SILVA FILHO, 2013; GARCIA; JESUS, 2015).

No entanto, esse sempre foi um campo de embates nas mais diversas instâncias. Sousa (2013), por exemplo, aponta como um dos principais argumentos contrários à implementação das Ações Afirmativas de acesso ao Ensino Superior, o princípio da igualdade política e jurídica dos cidadãos, presente na Constituição de 1988, Art. $5^{\circ}$. Segundo alguns opositores, as cotas, os bônus e as demais modalidades de promoção do ingresso nas IES públicas representariam uma ameaça a esse princípio (SOUSA, 2013). Por outro lado, diversos autores desconstroem argumentos como esse. Para os defensores, a reserva de vagas não contraria a Constituição de 1988, mas reforça a 
teoria de que o direito é insuficiente para atender a grupos étnicos excluídos e discriminados racialmente. Prates (2014, p. 71) observa que o ordenamento jurídico brasileiro "impõe a adoção das condições para a correção das desigualdades, o que sustenta a implementação das medidas de ação afirmativa".

Assim, entre argumentos contrários e favoráveis e muita pressão social, em 2012, o governo federal aprovou a Lei $\mathrm{n}^{\mathrm{o}}$. 12.711, que proporcionou, aos grupos historicamente excluídos, o acesso à educação superior. A referida lei dispõe sobre o ingresso nas universidades federais e nas instituições federais de ensino técnico de nível médio, direciona a Política de Ação Afirmativa e torna obrigatória a implantação das ações para a democratização do acesso ao Ensino Superior. Essa lei é resultado de mais de uma década de lutas e reivindicações de diferentes movimentos sociais, diversas tentativas de implantação de Ações Afirmativas nas universidades localizadas em diferentes Estados, debates, congressos e estudos que denunciavam o caráter excludente da educação superior brasileira (SOUSA, 2013). Agosto de 2016 foi o prazo estabelecido pela lei para que todas as instituições federais de Ensino Superior e Médio adequassem seus processos seletivos visando preencher, no mínimo, 50\% das vagas ofertadas com estudantes egressos de escolas públicas, consideradas suas subdivisões por renda e raça/cor, resultando em quatro grupos:

a) Estudantes autodeclarados pretos, pardos ou indígenas, com renda familiar bruta per capita igual ou inferior a 1,5 (um inteiro e cinco décimos) salário mínimo, e que tenham cursado integralmente o Ensino Médio em escolas públicas;

b) Estudantes autodeclarados pretos, pardos ou indígenas que, independentemente da renda (Art. 14, II, Portaria Normativa MEC $n^{\circ}$. 18/2012), tenham cursado integralmente o Ensino Médio em escolas públicas;

c) Estudantes que, independentemente da renda (Art. 14, II, Portaria Normativa MEC $\mathrm{n}^{\text {o }}$. 18/2012), tenham cursado integralmente o Ensino Médio em escolas públicas;

d) Estudantes com renda familiar bruta per capita igual ou inferior a 1,5 (um inteiro e cinco décimos) salário mínimo e que tenham cursado integralmente o Ensino Médio em escolas públicas.

As subdivisões apresentadas nas alíneas a, b, c, d serão, doravante, denominadas de PAA1, PAA2, PAA3 e PAA4, respectivamente, sendo PAA a abreviação de Política de Ação Afirmativa. Utilizaremos, também, a abreviação AC para nos referirmos aos estudantes da ampla concorrência. A Universidade Federal de Ouro Preto (UFOP) adotou em 2008 a Política de Ação Afirmativa para ingresso nos cursos de graduação. Esse processo teve início em 2003, culminando 
com sua aprovação em 2008. Tal política assegurava, no mínimo, 30\% das vagas disponibilizadas no vestibular (SANTOS, 2011). Em 2012, com o advento da Lei de Cotas, a Política de Ação Afirmativa da UFOP passou por um processo de adequação, visando ao cumprimento desse novo ordenamento jurídico. Assim, a partir do primeiro semestre de 2013, a UFOP substituiu a antiga política de cotas pela Lei $\mathrm{n}^{\circ}$. 12.711/2012. O percentual de oferta de vagas por modalidade de concorrência foi aumentando paulatinamente nos anos até atingir o limite mínimo estabelecido pela Lei (30\% de 2013/1 a 2014/2; 37,5\% de 2015/1 a 2016/1 e 50\% a partir de 2016/2).

Portanto, a política de ação afirmativa pode ser considerada um fenômeno social que merece ser investigado de modo a conhecer seu processo de implementação, impacto e efetividade. A Lei $\mathrm{n}^{\mathrm{o}}$. 12.711/2012 possibilitou o ingresso de vários estudantes dos meios populares na educação superior, mas ainda não se sabe muito sobre o percurso acadêmico desses indivíduos no âmbito universitário. Faz-se necessário desvendar suas experiências, oportunidades e desafios vivenciados durante sua permanência nesse nível de ensino.

\section{Metodologia}

Essa pesquisa analisa o percurso universitário de alunos participantes da política de ação afirmativa após o ingresso nos cursos de graduação presenciais da UFOP. Utilizamos metodologia quantitativa. Os métodos usados foram essencialmente: a) estatística descritiva: medidas de tendência central (média) e medidas de variabilidade ou dispersão (desvio padrão); b) testes de comparação de médias, para comprar grupos de alunos cotistas e de ampla concorrência: Teste T de student - método paramétrico usado quando a estatística de teste segue uma distribuição normal. Teste Wilcoxon - método não paramétrico utilizado quando não se pode assumir que a amostra é normalmente distribuída. Todos os testes foram realizados no software R e com $5 \%$ de significância.

As variáveis utilizadas para a comparação entre alunos de ampla concorrência e cotistas foram: nível socioeconômico, nota do ENEM, coeficiente geral da UFOP, reprovação, evasão e oportunidades acadêmicas (Quadro 1). 


\section{Quadro 1 - Descrição das variáveis utilizadas}

\begin{tabular}{|c|c|}
\hline Variável & Descrição \\
\hline $\begin{array}{l}\text { Nível } \\
\text { socioeconôm } \\
\text { ico (NSE) }\end{array}$ & $\begin{array}{l}\text { Variável latente estimada via Teoria da Resposta ao Item (TRI) a partir dos questionários } \\
\text { contextuais do ENEM e de informações da UFOP. Envolve itens dos questionários } \\
\text { relacionados com a escolaridade e a posição ocupacional dos pais do aluno e a renda familiar } \\
\text { (evidenciada pela posse de bens, uso de serviços e rendimento de fontes diversas) agregados } \\
\text { em uma única medida. O NSE dos alunos foi calculado em uma escala de } 0 \text { a } 10 \text {, que, } \\
\text { posteriormente, foi separada em sete faixas: } 1 \text { - "Mais baixo": } 0 \text { a } 3,39 ; 2 \text { - "Baixo": } 3,40 \text { a } \\
4,26 ; 3 \text { - "Médio baixo": 4,27 a 4,91; } 4 \text { - "Médio": } 4,92 \text { a 5,52; } 5 \text { - "Médio alto": } 5,53 \text { a } 6,26 \text {; } \\
6 \text { - "Alto": } 6,27 \text { a 7,14; } 7 \text { - "Mais alto": 7,15 a 10,00 (ALVES; SOARES; XAVIER, 2014; } \\
\text { RODRIGUES; MATOS; FERREIRA, 2017). Foi calculado para os alunos ingressantes no } \\
\text { primeiro semestre de 2013. }\end{array}$ \\
\hline $\begin{array}{c}\text { Nota } \\
\text { ENI }\end{array}$ & Nota do aluno no Exame Nacional do Ensino Médio (ENEM), para ingresso na UFOP \\
\hline $\begin{array}{l}\text { Coeficiente } \\
\text { Geral UFOP }\end{array}$ & $\begin{array}{l}\text { O coeficiente geral representa o índice que mede o desempenho acadêmico do discente na } \\
\text { UFOP. Assim, o coeficiente semestral representa a média das notas de todas as disciplinas } \\
\text { cursadas pelo aluno em cada período letivo e o coeficiente geral é a média dos coeficientes } \\
\text { semestrais. Consideramos o desempenho do aluno nos períodos de } 2013 / 1 \text { a } 2016 / 1 \text {, o que } \\
\text { corresponde ao coeficiente geral em sete períodos do curso. }\end{array}$ \\
\hline Reprovação & $\begin{array}{l}\text { A aprovação em disciplina está condicionada a uma pontuação igual ou superior a } 6,0 \text {, e as } \\
\text { faltas não podem ultrapassar } 25 \% \text { das aulas dadas no período. A UFOP possui três formas de } \\
\text { reprovação em disciplinas: reprovação por nota, reprovação por falta e reprovação por nota e } \\
\text { falta. Utilizamos somente a reprovação por nota, por abordar mais diretamente o critério de } \\
\text { rendimento. Portanto, verificamos o número de reprovações por nota em disciplinas dos } \\
\text { estudantes, decorridos sete semestres letivos }(2013 / 1 \text { a 2016/1). }\end{array}$ \\
\hline Evasão & $\begin{array}{l}\text { Consideramos evasão como a "saída do curso", seja por desligamento, cancelamento, } \\
\text { transferência, reopção ou abandono, reiterando que no momento da pesquisa nenhum dos } \\
\text { cursos da amostra havia concluído um ciclo (ingresso à diplomação). }\end{array}$ \\
\hline $\begin{array}{l}\text { Oportunidades } \\
\text { acadêmicas }\end{array}$ & $\begin{array}{l}\text { Oportunidades extracurriculares disponibilizadas aos estudantes de graduação durante o } \\
\text { percurso acadêmico na UFOP, como bolsas remuneradas e programas educacionais. } \\
\text { Consideramos: Extensão; Mobilidade acadêmica; Monitoria; PET - Programa de Educação } \\
\text { Tutorial; PIBIC - Programa Institucional de Bolsas de Iniciação Científica do CNPq; PIBIT } \\
\text { - Programa Institucional de Bolsas de Iniciação em Desenvolvimento Tecnológico e } \\
\text { Inovação do CNPq; PIP - Programa de Iniciação à Pesquisa; PIVIC - Programa Institucional } \\
\text { de Voluntários de Iniciação Científica; Proativa - Programa para a melhoria do ensino de } \\
\text { graduação; PROBIC - Programa Institucional de Bolsas de Iniciação Científica e Tecnológica } \\
\text { da FAPEMIG. }\end{array}$ \\
\hline
\end{tabular}

Fonte: Dados da UFOP (elaboração própria).

\section{Caracterização da amostra}

Os dados utilizados são provenientes de bancos da UFOP, mais especificamente do Sistema de Controle Acadêmico da Pró-reitoria de Graduação (PROGRAD). A amostra analisada é 
composta por 247 alunos ( 71 cotistas e 176 da ampla concorrência), todos ingressantes no primeiro semestre de 2013. Nesse estudo, selecionamos seis cursos para nossa amostra: Medicina, Nutrição, Engenharia Civil, Engenharia de Computação, Direito e Serviço Social. Nosso critério foi escolher uma amostra heterogênea, onde três grandes áreas de conhecimento estivessem representadas: Ciências da Saúde, Engenharias e Ciências Sociais Aplicadas. Além disso, dentro de cada área, selecionamos cursos de alto e baixo nível socioeconômico para garantir essa heterogeneidade. Apresentamos, na Tabela 1, os quantitativos de ocupação de vagas dos cursos da amostra.

Tabela 1 - Vagas dos cursos selecionados para a pesquisa 2013/1

\begin{tabular}{|c|c|c|c|c|c|c|c|c|}
\hline \multirow{3}{*}{$\begin{array}{c}\text { ÁREA DE } \\
\text { CONHECIMENTO }\end{array}$} & \multirow{3}{*}{ CURSO } & \multicolumn{7}{|c|}{ VAGAS PREENCHIDAS } \\
\hline & & \multirow[b]{2}{*}{$\mathrm{AC}$} & \multicolumn{5}{|c|}{ COTISTAS } & \multirow[b]{2}{*}{ TOTAL } \\
\hline & & & PAA1 & PAA2 & PAA3 & PAA4 & $\begin{array}{c}\text { TOTAL } \\
\text { PAA }\end{array}$ & \\
\hline \multirow{2}{*}{ Ciências da Saúde } & Medicina & 28 & 4 & 4 & 2 & 2 & 12 & 40 \\
\hline & Nutrição & 26 & 3 & 3 & 1 & 2 & 9 & 35 \\
\hline \multirow{2}{*}{ Engenharias } & Engenharia Civil & 25 & 4 & 3 & 2 & 2 & 11 & 36 \\
\hline & $\begin{array}{l}\text { Engenharia de } \\
\text { Computação }\end{array}$ & 26 & 3 & 5 & 1 & 2 & 11 & 37 \\
\hline \multirow{3}{*}{$\begin{array}{l}\text { Ciências Sociais } \\
\text { Aplicadas }\end{array}$} & Direito & 36 & 5 & 4 & 2 & 3 & 14 & 50 \\
\hline & Serviço Social & 35 & 4 & 3 & 3 & 4 & 14 & 49 \\
\hline & Total & 176 & 23 & 22 & 11 & 15 & 71 & 247 \\
\hline
\end{tabular}

Fonte: Dados da UFOP (elaboração própria).

Como as subdivisões por modalidade possuem números muito pequenos, optamos por aglutinar os dados de quem usou a política de ação afirmativa em nossas análises subsequentes unicamente como cotistas.

Considerando a faixa etária ideal para a educação superior estabelecida pela LDB, verificamos a faixa etária de ingresso dos estudantes cotistas e de ampla concorrência na UFOP, considerando a data de nascimento e a data de início do período letivo 2013/1 (13/05/2013) (Tabela 2). 
Tabela 2 - Faixa etária dos ingressantes na UFOP em 2013/1

\begin{tabular}{|c|c|c|c|c|c|c|c|c|c|c|c|c|c|}
\hline \multirow[b]{2}{*}{ Curso } & \multirow{2}{*}{ 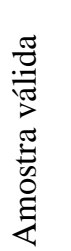 } & \multicolumn{4}{|c|}{ Ampla concorrência } & \multicolumn{4}{|c|}{ Cotista } & \multicolumn{4}{|c|}{ Geral } \\
\hline & & 目 & 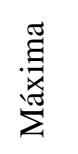 & 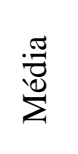 & 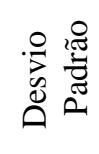 & 亶 & $\begin{array}{l}\text { 节 } \\
\text { 离 }\end{array}$ & 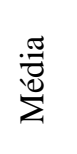 & 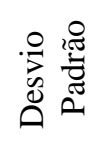 & 弯 & 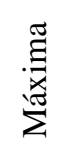 & 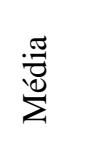 & 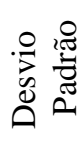 \\
\hline Medicina & 41 & 17,9 & 32,3 & 20,8 & 2,8 & 20,1 & 37,1 & 25,0 & 4,9 & 17,9 & 37,1 & 22,0 & 4,0 \\
\hline Nutrição & 34 & 17,8 & 30,5 & 21,1 & 3,1 & 17,7 & 35,0 & 20,9 & 5,9 & 17,7 & 35,0 & 21,1 & 3,9 \\
\hline $\begin{array}{l}\text { Engenharia } \\
\text { Civil }\end{array}$ & 36 & 17,7 & 20,9 & 18,9 & 0,8 & 17,7 & 27,5 & 20,1 & 2,7 & 17,7 & 27,5 & 19,3 & 1,6 \\
\hline Eng. de & & & & & & & & & & & & & \\
\hline $\begin{array}{l}\text { Computaçã } \\
\text { o }\end{array}$ & 32 & 17,1 & 25,7 & 19,9 & 2,4 & 17,7 & 27,7 & 20,1 & 2,8 & 17,1 & 27,7 & 20,0 & 2,5 \\
\hline Direito & 51 & 17,9 & 36,8 & 20,7 & 3,5 & 18,1 & 29,1 & 23,1 & 3,8 & 17,9 & 36,8 & 21,3 & 3,7 \\
\hline $\begin{array}{r}\text { Serviço } \\
\text { Social } \\
\end{array}$ & 47 & 17,9 & 58,1 & 27,4 & 10,4 & 17,8 & 39,8 & 26,3 & 7,6 & 17,8 & 58,1 & 27,1 & 9,6 \\
\hline Geral cursos & 241 & 17,1 & 58,1 & 21,5 & 5,9 & 17,7 & 39,8 & 22,6 & 5,4 & 17,1 & 58,1 & 21,8 & 5,8 \\
\hline
\end{tabular}

Fonte: Dados da UFOP (elaboração própria).

Nota: Faixa etária em anos e meses. A amostra válida não coincide com o número de vagas ofertadas devido a alguns dados ausentes no banco de dados.

A média das idades nos mostra que os cursos da amostra são frequentados predominantemente por jovens, apesar desse valor médio estar um pouco acima da idade prevista para o ingresso na educação superior. As engenharias possuem um público mais jovem e mais homogêneo, sendo os cursos com menor variabilidade na idade (menores desvios padrão). Em relação à modalidade de concorrência, verifica-se, na maioria dos cursos, que o estudante cotista se insere no Ensino Superior um pouco mais velho. Nutrição e Engenharia de Computação são os cursos em que as médias etárias entre estudantes da ampla concorrência e cotistas mais se aproximam e, nos cursos de Medicina e Direito, essa diferença é mais acentuada.

Na maioria dos cursos estudados, os índices de ocupação feminina ultrapassam os 60\%, com exceção para as Engenharias Civil e de Computação. As mulheres também ocupam a maioria das vagas destinadas aos estudantes cotistas, novamente com exceção para as Engenharias Civil e de Computação (Tabela 3). 
Tabela 3 - Gênero dos estudantes UFOP 2013/1 de acordo com a modalidade de ingresso

\begin{tabular}{|c|c|c|c|c|c|c|c|c|c|c|c|}
\hline \multirow{3}{*}{ Curso } & \multirow{3}{*}{ 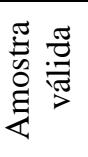 } & \multicolumn{5}{|c|}{ Ampla concorrência } & \multicolumn{5}{|c|}{ Cotista } \\
\hline & & \multicolumn{2}{|c|}{ Mulheres } & \multicolumn{2}{|c|}{ Homens } & \multirow{2}{*}{ Total } & \multicolumn{2}{|c|}{ Mulheres } & \multicolumn{2}{|c|}{ Homens } & \multirow{2}{*}{ Total } \\
\hline & & Quant. & $\%$ & Quant. & $\%$ & & Quant. & $\%$ & Quant. & $\%$ & \\
\hline Medicina & 41 & 16 & $55,2 \%$ & 13 & $44,8 \%$ & 29 & 9 & $75,0 \%$ & 3 & $25,0 \%$ & 12 \\
\hline Nutrição & 34 & 18 & $72,0 \%$ & 7 & $28,0 \%$ & 25 & 7 & $77,8 \%$ & 2 & $22,2 \%$ & 9 \\
\hline Eng. Civil & 36 & 9 & $36,0 \%$ & 16 & $64,0 \%$ & 25 & 5 & $45,5 \%$ & 6 & $54,5 \%$ & 11 \\
\hline $\begin{array}{l}\text { Eng. de } \\
\text { Computação }\end{array}$ & 32 & 4 & $18,2 \%$ & 18 & $81,8 \%$ & 22 & 1 & $10,0 \%$ & 9 & $90,0 \%$ & 10 \\
\hline Direito & 51 & 23 & $62,2 \%$ & 14 & $37,8 \%$ & 37 & 8 & $57,1 \%$ & 6 & $42,9 \%$ & 14 \\
\hline Serviço Social & 47 & 28 & $84,8 \%$ & 5 & $15,2 \%$ & 33 & 9 & $64,3 \%$ & 5 & $35,7 \%$ & 14 \\
\hline Total cursos & 241 & 98 & $57,3 \%$ & 73 & $42,7 \%$ & 171 & 39 & $55,7 \%$ & 31 & $44,3 \%$ & 70 \\
\hline
\end{tabular}

Fonte: Dados da UFOP (elaboração própria).

O curso de Nutrição detém o maior percentual de mulheres na ocupação de vagas para cotistas (77,8\%), seguido do curso de Medicina (75,0\%). Já nas Engenharias Civil e de Computação, os percentuais de cotistas femininos são, respectivamente, $45,5 \%$ e 10,0\%, o que corresponde, nesse último caso, a um percentual mais baixo entre os cursos da amostra.

Já para a cor/raça dos alunos, os autodeclarados pardos preenchem 52,9\% das vagas destinadas aos cotistas e os pretos $15,7 \%$. Nos cursos da amostra, os brancos são maioria nos cursos de maior prestígio, como nos cursos de Medicina e Direito (Tabela 4).

Tabela 4 - Ocupação de vagas pelos cotistas nos cursos da amostra, segundo a cor/raça

\begin{tabular}{|c|c|c|c|c|c|c|c|c|c|c|}
\hline \multirow[b]{2}{*}{ Curso } & \multicolumn{6}{|c|}{ Ampla concorrência } & \multicolumn{4}{|c|}{ Cotistas } \\
\hline & 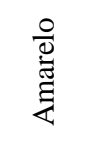 & 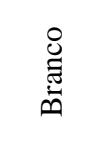 & 常 & $\frac{9}{0}$ & 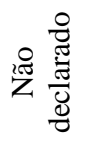 & స్త్ర & 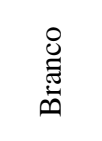 & : & $\begin{array}{l}\frac{0}{0} \\
\frac{0}{2}\end{array}$ & 평 \\
\hline \multirow{2}{*}{ Medicina } & 0 & 21 & 7 & 0 & 1 & 29 & 4 & 6 & 2 & 12 \\
\hline & $0,0 \%$ & $72,4 \%$ & $24,1 \%$ & $0,0 \%$ & $3,4 \%$ & & $33,3 \%$ & $50,0 \%$ & $16,7 \%$ & \\
\hline \multirow{2}{*}{ Nutrição } & 1 & 15 & 7 & 2 & 0 & 25 & 2 & 5 & 2 & 9 \\
\hline & $4,0 \%$ & $60,0 \%$ & $28,0 \%$ & $8,0 \%$ & $0,0 \%$ & & $22,2 \%$ & $55,6 \%$ & $22,2 \%$ & \\
\hline \multirow{2}{*}{$\begin{array}{l}\text { Engenharia } \\
\text { Civil }\end{array}$} & 1 & 14 & 10 & 0 & 0 & 25 & 4 & 7 & 0 & 11 \\
\hline & $4,0 \%$ & $56,0 \%$ & $40,0 \%$ & $0,0 \%$ & $0,0 \%$ & & $36,4 \%$ & $63,6 \%$ & $0,0 \%$ & \\
\hline \multirow{2}{*}{$\begin{array}{l}\text { Eng. de } \\
\text { Computação }\end{array}$} & 0 & 10 & 9 & 2 & 1 & 22 & 3 & 5 & 2 & 10 \\
\hline & $0,0 \%$ & $45,5 \%$ & $40,9 \%$ & $9,1 \%$ & $4,5 \%$ & & $30,0 \%$ & $50,0 \%$ & $20,0 \%$ & \\
\hline Direito & 1 & 25 & 6 & 3 & 2 & 37 & 4 & 9 & 1 & 14 \\
\hline
\end{tabular}




\begin{tabular}{|c|c|c|c|c|c|c|c|c|c|c|}
\hline & $2,7 \%$ & $67,6 \%$ & $16,2 \%$ & $8,1 \%$ & $5,4 \%$ & & $28,6 \%$ & $64,3 \%$ & $7,1 \%$ & \\
\hline \multirow{2}{*}{$\begin{array}{l}\text { Serviço } \\
\text { Social }\end{array}$} & 1 & 17 & 12 & 3 & 0 & \multirow[t]{2}{*}{33} & 5 & 5 & 4 & \multirow[t]{2}{*}{14} \\
\hline & $3,0 \%$ & $51,5 \%$ & $36,4 \%$ & $9,1 \%$ & $0,0 \%$ & & $35,7 \%$ & $35,7 \%$ & $28,6 \%$ & \\
\hline \multirow{2}{*}{ Total cursos } & 4 & 102 & 51 & 10 & 4 & \multirow[t]{2}{*}{171} & 22 & 37 & 11 & \multirow[t]{2}{*}{70} \\
\hline & $2,3 \%$ & $59,6 \%$ & $29,8 \%$ & $5,8 \%$ & $2,3 \%$ & & $31,4 \%$ & $52,9 \%$ & $15,7 \%$ & \\
\hline
\end{tabular}

Fonte: Dados da UFOP (elaboração própria).

\section{Resultados e discussões}

\subsection{Nível socioeconômico}

Apresentamos, na Tabela 5, o NSE dos cursos selecionados nessa pesquisa, distribuídos de acordo com a área de conhecimento.

\section{Tabela 5 - NSE dos cursos da amostra}

\begin{tabular}{lcccccc}
\hline \multirow{2}{*}{$\begin{array}{c}\text { Área de } \\
\text { Conhecimento }\end{array}$} & Curso & $\begin{array}{c}\text { Amostra } \\
\text { válida }\end{array}$ & $\begin{array}{c}\text { NSE } \\
\text { Mínimo }\end{array}$ & $\begin{array}{c}\text { NSE } \\
\text { Máximo }\end{array}$ & $\begin{array}{c}\text { Média } \\
\text { NSE }\end{array}$ & Desvio Padrão \\
\hline Ciências da Saúde & Medicina & 41 & 2,79 & 7,66 & 5,72 & 1,30 \\
\cline { 2 - 6 } & Nutrição & 20 & 2,89 & 8,64 & 5,44 & 1,42 \\
\hline \multirow{2}{*}{\begin{tabular}{l} 
Engenharia Civil \\
\cline { 2 - 6 }
\end{tabular}} & $\begin{array}{c}\text { Engenharia de } \\
\text { Computação }\end{array}$ & 36 & 3,20 & 7,84 & 5,58 & 1,11 \\
\hline $\begin{array}{l}\text { Ciências Sociais } \\
\text { Aplicadas }\end{array}$ & Direito & 46 & 1,35 & 7,74 & 5,37 & 1,41 \\
\cline { 2 - 6 } & Serviço Social & 24 & 1,04 & 5,78 & 4,17 & 1,35 \\
\hline
\end{tabular}

Fonte: Elaborado pelos autores a partir dos dados de Rodrigues, Matos e Ferreira (2017).

Conforme indicado na Tabela 5, os cursos de Serviço Social e de Engenharia de Computação possuem os menores valores de nível socioeconômico (4,17 e 4,56, respectivamente). O curso de Serviço Social possui o terceiro menor NSE entre os cursos da UFOP ofertados em 2013/1, estando à frente apenas dos cursos de Educação Física e de Artes Cênicas (RODRIGUES; MATOS; FERREIRA, 2017). Os cursos de Medicina e de Engenharia Civil detêm os maiores valores de nível socioeconômico médio (5,72 e 5,58, respectivamente) entre os cursos da amostra, sendo o curso de Medicina aquele que detém o maior NSE médio dos cursos da UFOP. Também 
observamos uma grande amplitude entre o NSE máximo e o NSE mínimo na maioria dos cursos. O desvio padrão indica que os cursos de Nutrição e Direito possuem a maior variabilidade do nível socioeconômico dos alunos. Para melhor entendermos a realidade e compararmos os NSE dos cursos selecionados, é necessário observarmos a distribuição dos estudantes cotistas e de ampla concorrência por faixas de NSE (Gráficos de 1 a 6).

Podemos verificar que a distribuição dos alunos nas faixas de NSE são bem diferentes nos seis cursos da amostra. Os cursos de Medicina e Direito possuem a maior concentração de alunos em faixas de nível socioeconômico mais elevado. Já no curso de Nutrição, a maioria dos estudantes ocupa as faixas médias de NSE, e os estudantes cotistas concentram-se exclusivamente no grupo de NSE "baixo".

Gráfico 1 - Nível socioeconômico dos estudantes UFOP 2013/1 - Medicina

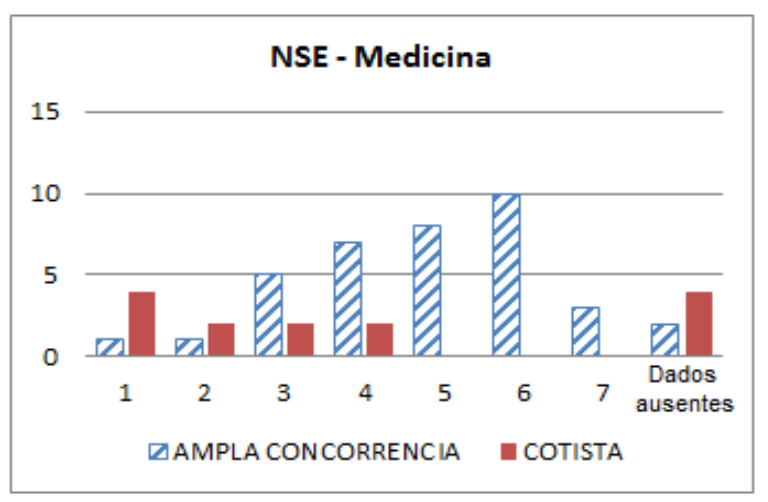

Gráfico 3 - Nível socioeconômico dos estudantes UFOP 2013/1 - Engenharia Civil

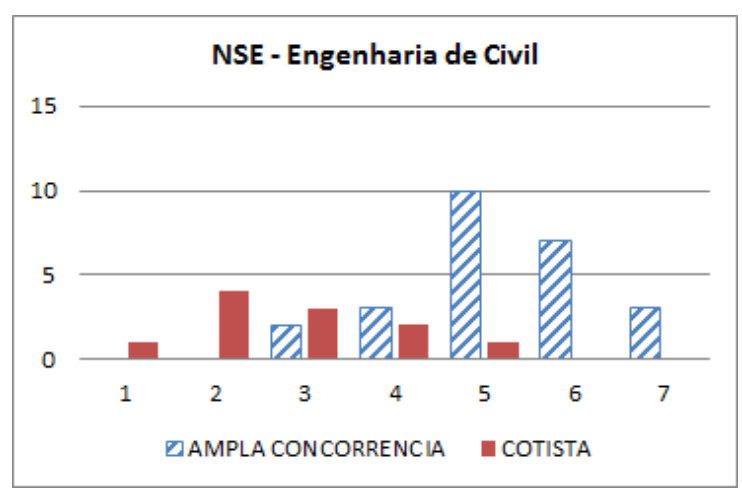

Gráfico 2 - Nível socioeconômico dos estudantes UFOP 2013/1 - Nutrição

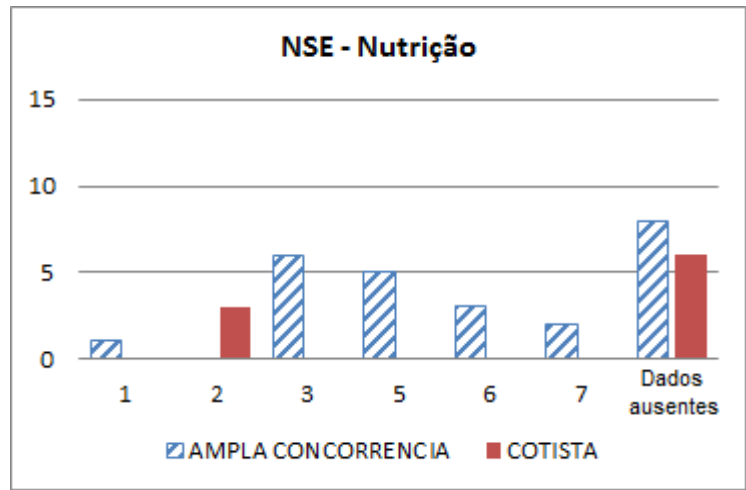

Gráfico 4 - Nível socioeconômico estudantes UFOP 2013/1 - Eng. de Computação

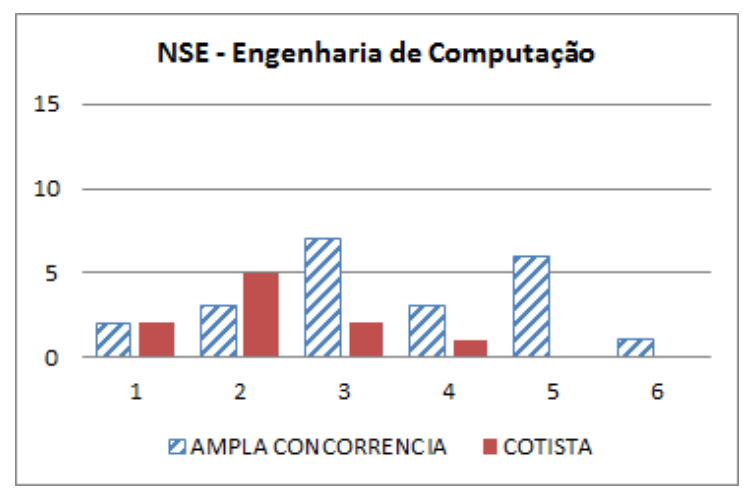



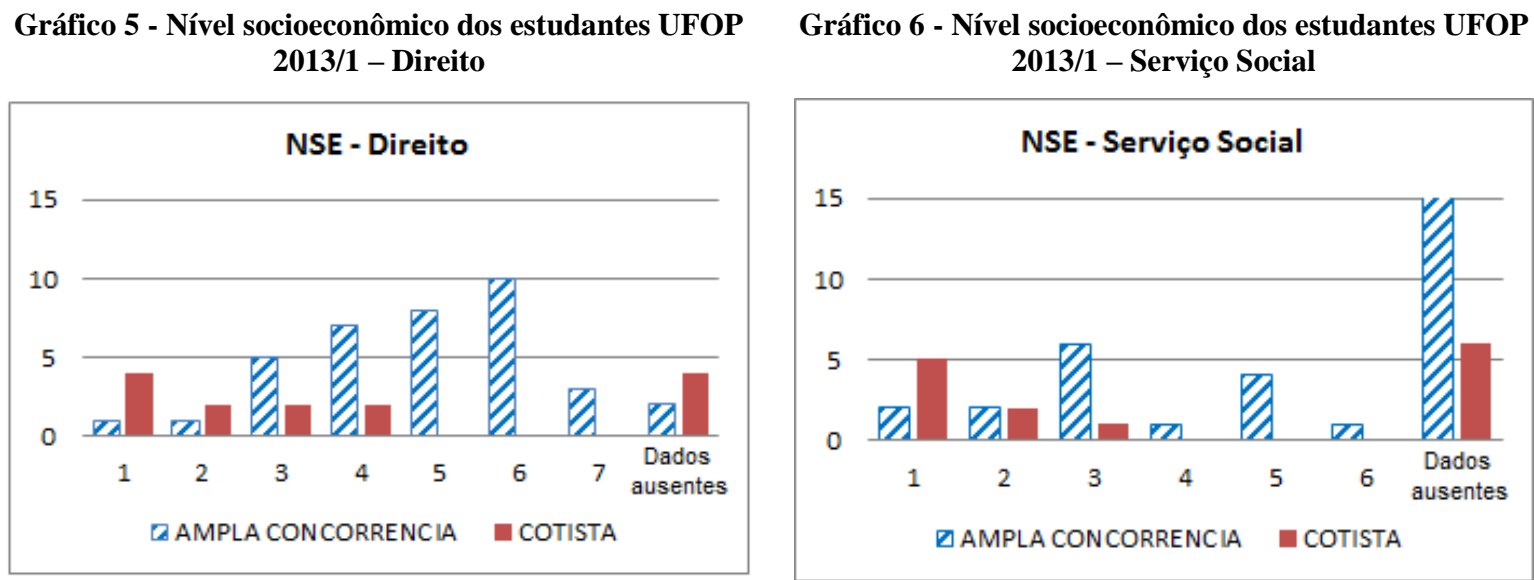

Fonte: Dados da UFOP (elaboração própria).

Nota: GRUPOS: 1 "Mais baixo", 2 "Baixo"; 3 "Médio baixo"; 4 "Médio"; 5 "Médio alto"; 6 "Alto"; 7 "Mais alto

Os cursos de Serviço Social e Engenharia de Computação concentram-se nas faixas mais baixas do NSE. As faixas mais baixas do NSE apresentadas nos cursos de Engenharia Civil, Medicina e Serviço Social correspondem a estudantes que participaram da reserva de vagas para candidatos que atendem ao critério de renda familiar per capita igual ou inferior a 1,5 salário mínimo. Assim, existe uma tendência em todos os cursos da amostra, embora não de maneira uniforme, da presença de alunos cotistas nas faixas mais baixas do NSE.

Para a amostra como um todo, o Teste $\mathrm{T}$ comprovou que existe uma diferença estatisticamente significativa entre o nível socioeconômico de alunos cotistas e de ampla concorrência, sendo maior o NSE de alunos de ampla concorrência (média ampla concorrência= 5.78 , média cotista $=3.98$, p-valor 0,000 ). $\mathrm{O}$ mesmo padrão se repete quando analisamos os cursos separadamente (Teste T ou Teste Wilcoxon, dependendo do curso). Segundo Rodrigues, Matos e Ferreira (2017), esse é um resultado empírico de que as políticas afirmativas estão desempenhando uma função esperada de inclusão social.

\subsection{Nota do Exame Nacional do Ensino Médio (ENEM)}


A UFOP utilizava parcialmente, desde 1999, o resultado do ENEM na composição das notas dos candidatos nos processos seletivos para ingresso nos cursos de graduação presenciais e a distância. Para análise do desempenho dos estudantes ingressantes na UFOP em 2013/1, utilizaremos a pontuação obtida no ENEM (Tabela 6).

Tabela 6 - Pontuação no ENEM 2013/1

\begin{tabular}{|c|c|c|c|c|c|c|c|c|c|c|c|c|}
\hline \multirow[b]{2}{*}{ Curso } & \multicolumn{4}{|c|}{ Ampla concorrência } & \multicolumn{4}{|c|}{ Cotista } & \multicolumn{4}{|c|}{ Geral } \\
\hline & $\stackrel{\varrho}{\stackrel{\Xi}{\Xi}}$ & 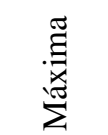 & 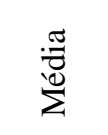 & 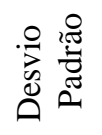 & 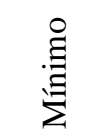 & 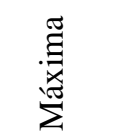 & $\frac{\sqrt[\pi]{0}}{\sum}$ & 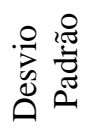 & $\stackrel{\ominus}{\stackrel{\Xi}{\Xi}}$ & 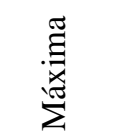 & $\sum_{i=\frac{\pi}{2}}^{: 0}$ & 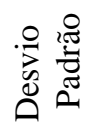 \\
\hline Medicina & 763,44 & 809,00 & 784,13 & 10,91 & 713,84 & 791,60 & 751,68 & 26,27 & 713,84 & 809,00 & 774,39 & 22,45 \\
\hline Nutrição & 588,84 & 700,66 & 643,01 & 30,46 & 537,40 & 661,82 & 625,76 & 41,36 & 537,40 & 700,66 & 638,58 & 33,81 \\
\hline $\begin{array}{l}\text { Engenharia } \\
\text { Civil }\end{array}$ & 697,92 & 745,68 & 722,94 & 12,69 & 636,32 & 736,26 & 690,72 & 33,54 & 636,32 & 745,68 & 713,10 & 25,66 \\
\hline $\begin{array}{l}\text { Eng. de } \\
\text { Computação }\end{array}$ & 605,66 & 699,42 & 660,37 & 27,10 & 554,02 & 687,74 & 643,25 & 40,60 & 554,02 & 699,42 & 655,02 & 32,27 \\
\hline Direito & 694,60 & 769,74 & 724,51 & 18,81 & 642,92 & 721,56 & 686,50 & 25,89 & 642,92 & 769,74 & 713,87 & 26,98 \\
\hline Serviço Social & 560,54 & 676,62 & 610,19 & 32,44 & 520,10 & 646,14 & 584,35 & 37,64 & 520,10 & 676,62 & 602,65 & 35,66 \\
\hline Total & 560,54 & 809,00 & 690,67 & 64,36 & 520,10 & 791,60 & 663,92 & 64,60 & 520,10 & 809,00 & 682,90 & 65,44 \\
\hline
\end{tabular}

Fonte: Dados da UFOP (elaboração própria).

Conforme descrito na Tabela 6, podemos observar que as maiores pontuações obtidas no ENEM encontram-se no curso de Medicina, tanto para os estudantes cotistas $(791,60)$, quanto da ampla concorrência $(809,00)$. Medicina também registra a maior média $(774,39)$ entre os cursos analisados, seguido de Direito $(713,87)$ e de Engenharia Civil $(713,10)$. Uma das explicações para que as pontuações dos estudantes dos cursos de Medicina, Engenharia Civil e Direito sejam mais altas está no nível socioeconômico mais elevado dos concorrentes desses cursos (RODRIGUES; MATOS; FERREIRA, 2017), por serem cursos de maior prestígio, altamente concorridos e com candidatos mais preparados. O desvio padrão nos mostra o quanto de variação ou "dispersão" existe em relação à média. Quanto maior o desvio padrão, maior a variabilidade dos dados. Os cursos de Serviço Social, de Nutrição e de Engenharia de Computação detêm a maior variabilidade na pontuação do ENEM. 
Em todos os cursos analisados, os alunos de ampla concorrência obtiveram médias maiores do que os estudantes cotistas. Nesse sentido, em alguns casos, não fosse a reserva de vagas, o candidato não seria admitido no curso, inclusive pela classificação ser definida, muitas vezes, nas casas decimais da pontuação. Por outro lado, verificamos também bons resultados de estudantes cotistas, com pontuações maiores do que de candidatos da ampla concorrência, e que não necessitariam da reserva para entrarem no curso. Considerando os cursos da amostra como um todo, o Teste Wilcoxon indicou que há diferença estatisticamente significativa (p-valor 0,017) entre a pontuação média do ENEM dos cotistas e dos estudantes da ampla concorrência, sendo os últimos detentores das maiores notas. Outros testes estatísticos (Teste T ou Teste Wilcoxon, dependendo do curso) comprovaram ainda que há diferença estatisticamente significativa entre a maioria dos cursos da amostra, com nota do ENEM dos estudantes da ampla concorrência maior do que a nota dos estudantes cotistas, com exceção dos cursos de Nutrição e de Engenharia de Computação, que não apresentaram diferença estatisticamente significativa na pontuação do ENEM entre os participantes nas diferentes modalidades de concorrência. Esses dados comprovam que os cursos que recebem alunos com os melhores resultados no processo seletivo são aqueles com o maior NSE.

\subsection{Desempenho acadêmico na UFOP (coeficiente geral)}

Em relação ao coeficiente geral, é importante mencionar um aspecto técnico. Avaliações externas, como o ENEM, são baseadas em testes padronizados e permitem comparações entre resultados de estudantes e cursos. O coeficiente geral, por sua vez, é baseado em uma ou mais avaliações de sala de aula num determinado período, diversificadas em sua forma e determinadas por características inerentes ao professor (mais ou menos exigente). Além disso, cada estudante pode cursar disciplinas com diferentes professores. Portanto, essas avaliações internas (de sala de aula) não permitem comparações entre alunos, cursos e áreas. Nesse sentido, não iremos comparar cursos diferentes. Faremos comparações apenas dentro dos próprios cursos, que, mesmo assim, devem ser vistas com cautela (Tabela 7). 
Tabela 7 - Coeficiente geral de alunos cotistas e de ampla concorrência nos cursos da amostra

\begin{tabular}{|c|c|c|c|c|c|c|c|c|c|c|c|c|}
\hline \multirow[b]{2}{*}{ Curso } & \multicolumn{4}{|c|}{ Ampla concorrência } & \multicolumn{4}{|c|}{ Cotista } & \multicolumn{4}{|c|}{ Geral } \\
\hline & 目 & 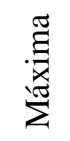 & 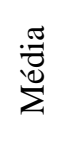 & 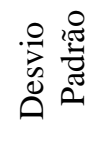 & 恋 & 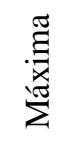 & $\frac{\pi}{\stackrel{\pi}{*}}$ & 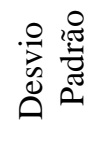 & 高 & 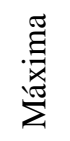 & 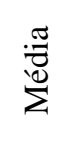 & 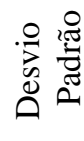 \\
\hline Medicina & 5,8 & 8,9 & 7,9 & 0,7 & 7,0 & 8,5 & 7,8 & 0,5 & 5,8 & 8,9 & 7,8 & 0,6 \\
\hline Nutrição & 2,6 & 8,7 & 6,3 & 1,9 & 3,5 & 9,0 & 7,1 & 2,5 & 2,6 & 9,0 & 6,5 & 2,0 \\
\hline Engenharia Civil & 4,5 & 8,6 & 6,4 & 1,1 & 5,2 & 8,5 & 6,9 & 1,4 & 4,5 & 8,6 & 6,5 & 1,2 \\
\hline $\begin{array}{l}\text { Eng. } \\
\text { Computação }\end{array}$ & 5,1 & 8,6 & 6,6 & 1,4 & 3,6 & 7,9 & 6,2 & 2,3 & 3,6 & 8,6 & 6,5 & 1,6 \\
\hline Direito & 5,0 & 9,1 & 7,5 & 1,1 & 6,0 & 9,2 & 7,6 & 0,9 & 5,0 & 9,2 & 7,5 & 1,1 \\
\hline Serviço Social & 4,3 & 8,8 & 7,7 & 1,6 & 6,0 & 8,5 & 7,4 & 0,8 & 4,3 & 8,8 & 7,5 & 1,1 \\
\hline Total cursos & 2,6 & 9,1 & 7,2 & 1,3 & 3,5 & 9,2 & 7,4 & 1,2 & 2,6 & 9,2 & 7,2 & 1,3 \\
\hline
\end{tabular}

Fonte: Dados da UFOP (elaboração própria).

Conforme indicado na Tabela 7, na maioria dos casos, as médias de coeficiente geral de cada curso são próximas ao compararmos cotistas e ampla concorrência. O curso de Nutrição apresenta a maior variabilidade (desvio padrão) entre os coeficientes de estudantes cotistas e da ampla concorrência, o que pode indicar maior heterogeneidade de desempenho entre os alunos do curso.

Conforme apresentado na Tabela 6, na maioria dos cursos, os estudantes da ampla concorrência apresentam melhores resultados no ENEM. Contudo, na Tabela 7, observamos que, em relação ao coeficiente geral, os resultados médios quase se equiparam entre os estudantes do mesmo curso e a variabilidade é baixa na maioria dos casos. Para a amostra como um todo, o Teste Wilcoxon indicou que não existe diferença estatisticamente significativa (p-valor 0,946) entre os coeficientes dos estudantes cotistas e de ampla concorrência nos cursos selecionados. O mesmo padrão se repete quando analisamos os cursos separadamente (Teste $\mathrm{T}$ ou Teste Wilcoxon, dependendo do curso). Ou seja: o desempenho acadêmico após o ingresso na universidade é equivalente entre cotistas e estudantes da ampla concorrência, mesmo que a pontuação do ENEM 
(entrada na universidade) tenha sido maior para os alunos de ampla concorrência da maioria dos cursos. Esse foi um dos resultados mais importantes da presente pesquisa.

\subsection{Reprovação}

Os nossos resultados revelam que os maiores índices de reprovações ocorrem nos períodos iniciais. Consideradas as proporções de ingresso de estudantes cotistas e da ampla concorrência (30\% das vagas reservadas para cotistas), podemos perceber que há uma certa similaridade entre as reprovações de estudantes das diferentes modalidades de concorrência, apontando para uma maior ocorrência de reprovações durante os primeiros períodos do curso. Essa tendência pode ser verificada em todos os cursos da amostra, exceto no curso de Engenharia Civil, que apresenta diversificados números de reprovações ao longo dos períodos. Também observamos taxas de reprovação mais altas nos cursos da área de Engenharias (Gráficos 7 a 12).

De acordo com Coullon (2008), essa maior incidência de reprovações nos primeiros períodos do curso pode estar associada a diversos fatores, como, por exemplo: o processo de transição do Ensino Médio para o Ensino Superior, a adaptação ao novo ambiente acadêmico, as rupturas e diversas mudanças na vida estudantil e pessoal que esse processo acarreta (COULLON, 2008). Por outro lado, também existem outras hipóteses: tanto o estudante da ampla concorrência quanto o cotista podem ter se matriculado em um curso com a intenção de ser aprovado posteriormente em outro curso, o que torna as reprovações nos primeiros períodos apenas o retrato de uma passagem desinteressada.

Ao compararmos a reprovação de estudantes cotistas e de ampla concorrência, na amostra total, não encontramos diferença estatisticamente significativa. Assim, esses resultados nos levam a crer que, ao longo do curso, os estudantes se adaptam ao novo meio, passam a conhecer melhor as regras do jogo escolar, aprendem o ofício de aluno e se tornam universitários (COULLON, 2008), indiferente da modalidade de ingresso. 
Gráfico 7 - Número de reprovações por nota no curso de Medicina

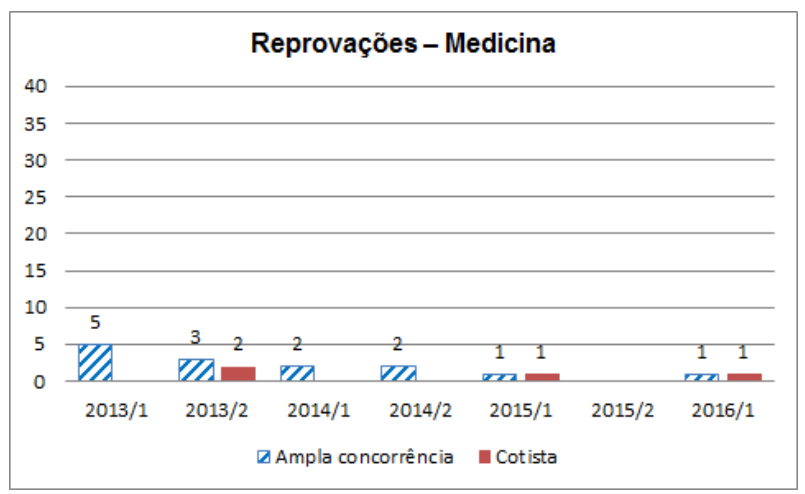

Gráfico 9 - Número de reprovações por nota no curso de Engenharia Civil

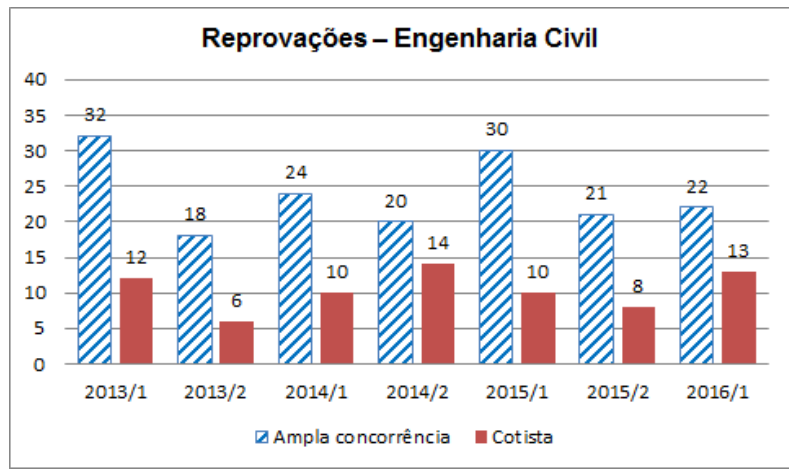

Gráfico 11 - Número de reprovações por nota no curso de Direito

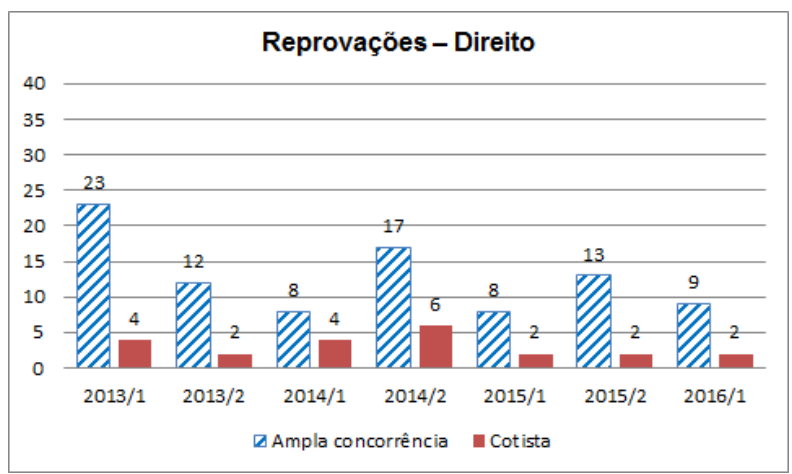

Fonte: Dados da UFOP (elaboração própria).
Gráfico 8 - Número de reprovações por nota no curso de Nutrição

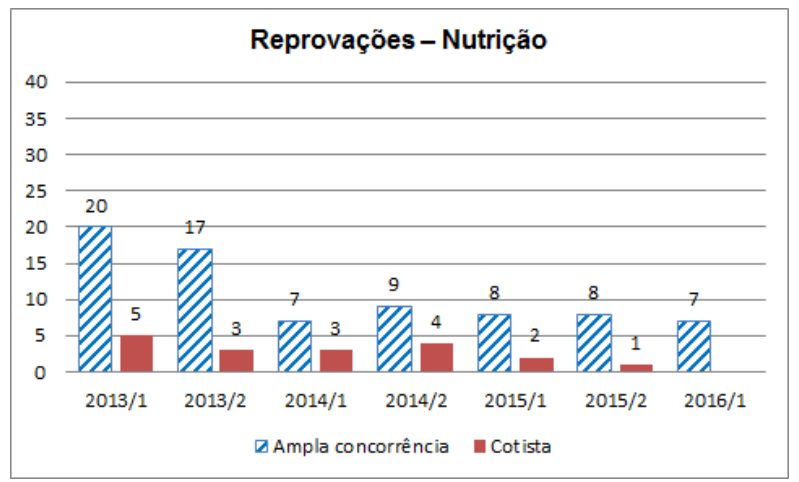

Gráfico 10 - Número de reprovações por nota no curso de Engenharia de Computação

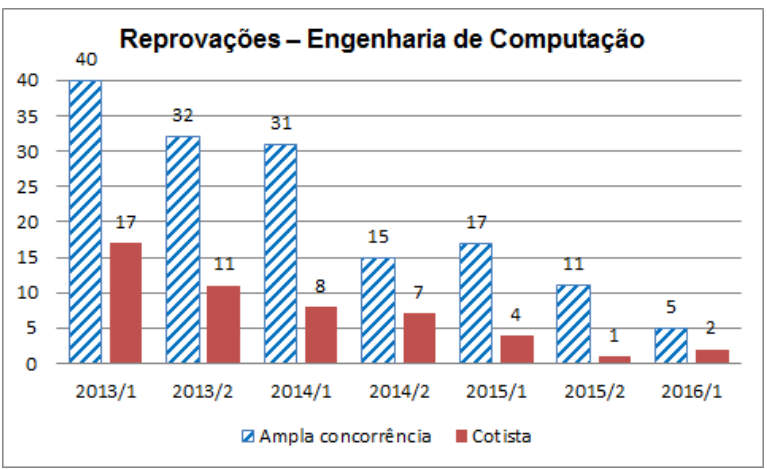

Gráfico 12 - Número de reprovações por nota no curso de Serviço Social

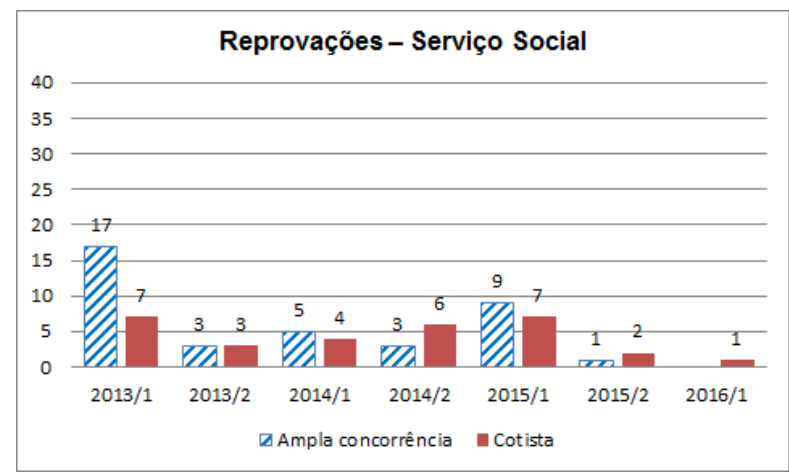




\subsection{Evasão}

Na Tabela 8, apresentamos dados sobre a situação dos alunos (matriculados e evadidos) ingressantes 2013/1 nos cursos em estudo até o primeiro período letivo de 2016.

Tabela 8 - Situação dos estudantes ingressantes em 2013/1 (matriculados e evadidos) até 2016/1

\begin{tabular}{|c|c|c|c|c|c|c|c|c|c|c|c|c|c|c|c|}
\hline \multirow[b]{2}{*}{ Cursos } & \multirow{2}{*}{ 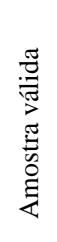 } & \multicolumn{5}{|c|}{ Ampla concorrência } & \multicolumn{5}{|c|}{ Cotista } & \multicolumn{4}{|c|}{ Geral } \\
\hline & & $\begin{array}{l}\frac{8}{\pi} \\
\frac{\pi}{\bar{J}} \\
\stackrel{\Xi}{ \pm} \\
\sum\end{array}$ & $\%$ & 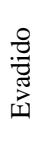 & $\%$ & 丞 & 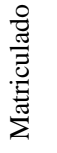 & $\%$ & 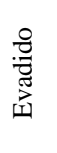 & $\%$ & हैँ & 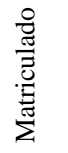 & $\%$ & 胥 & $\%$ \\
\hline Medicina & 41 & 27 & 93,1 & 2 & 6,9 & 29 & 12 & 100,0 & 0 & 0,0 & 12 & 39 & 95,1 & 2 & 4,9 \\
\hline Nutrição & 34 & 12 & 48,0 & 13 & 52,0 & 25 & 4 & 44,4 & 5 & 55,6 & 9 & 16 & 47,1 & 18 & 52,9 \\
\hline $\begin{array}{l}\text { Engenharia } \\
\text { Civil }\end{array}$ & 36 & 17 & 68,0 & 8 & 32,0 & 25 & 8 & 72,7 & 3 & 27,3 & 11 & 25 & 69,4 & 11 & 30,6 \\
\hline $\begin{array}{l}\text { Eng. De } \\
\text { Computação }\end{array}$ & 32 & 8 & 36,4 & 14 & 63,6 & 22 & 3 & 30,0 & 7 & 70,0 & 10 & 11 & 34,4 & 21 & 65,6 \\
\hline Direito & 51 & 27 & 73,0 & 10 & 27,0 & 37 & 12 & 85,7 & 2 & 14,3 & 14 & 39 & 76,5 & 12 & 23,5 \\
\hline Serviço Social & 47 & 7 & 21,2 & 26 & 78,8 & 33 & 11 & 78,6 & 3 & 21,4 & 14 & 18 & 38,3 & 29 & 61,7 \\
\hline Total & 241 & 98 & 57,3 & 73 & 42,7 & 171 & 50 & 71,4 & 20 & 28,6 & 70 & 148 & 61,4 & 93 & 38,6 \\
\hline
\end{tabular}

Fonte: Dados da UFOP (elaboração própria).

Verifica-se, na Tabela 8, com exceção do curso de Medicina, uma taxa de evasão bem mais alta do que a média nacional, que, em 2013, segundo o Censo da Educação Superior, era de 17,8\% na rede pública (INEP, 2015). A Engenharia Civil é o curso de NSE alto com maior índice de evasão (30,6\%). Observa-se, também, uma grande discrepância entre a taxa de evasão dos cursos de acordo com o NSE: os cursos com menor NSE ultrapassam em 50\% o número de evadidos. Os cursos de Engenharia de Computação e de Serviço Social possuem os índices mais preocupantes de evasão, ultrapassando os $60 \%$. No curso de Medicina, não foi registrado nenhum desligamento ou cancelamento entre os cotistas, e, no curso de Direito, apenas dois se desvincularam da UFOP, diferentemente dos cursos de Engenharia de Computação e de Nutrição, que apresentaram os maiores índices de evasão entre os cotistas (70\% e 55,6\%, respectivamente).

De acordo com os Gráficos 13 a 18, podemos perceber que há uma tendência geral de que as evasões ocorram mais nos primeiros períodos dos cursos, tanto entre os estudantes cotistas quanto entre os estudantes da ampla concorrência. 
Além das causas que apontamos anteriormente para reprovações e evasões durante os períodos iniciais do curso (COULLON, 2008), o SiSU tem proporcionado ao estudante uma maior mobilidade entre cursos e universidades, principalmente diante da possibilidade de utilizar a pontuação do ENEM em mais de um processo seletivo por ano e de aproveitamento de disciplinas cursadas com aprovação, facilitando para o estudante indeciso mudar de curso nos primeiros períodos.

Entre os cotistas que responderam o questionário socioeconômico, 93\% dos estudantes evadidos pertencem aos grupos de NSE "Mais baixo", "Baixo" e "Médio baixo", e apenas um deles, cotista do curso de Engenharia Civil, justificou sua saída por motivo financeiro. Na amostra como um todo, não existe diferença estatisticamente significativa entre a proporção de evasão dos estudantes cotistas e de ampla concorrência. O mesmo padrão se repete em todos os cursos, com exceção do Serviço Social. Nesse curso, a evasão entre os estudantes da ampla concorrência é significativamente maior que entre os cotistas. Chama-nos a atenção os expressivos índices de evasão nos cursos da UFOP, em especial nos cursos de baixo NSE, o que requer da instituição medidas urgentes para enfrentar o problema. 
Gráfico 13 - Evasão por períodos - Medicina

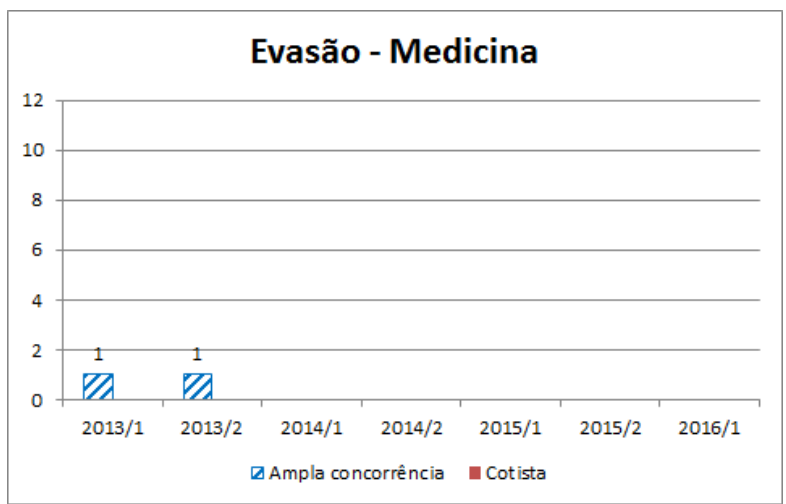

Gráfico 15 - Evasão por períodos - Engenharia Civil

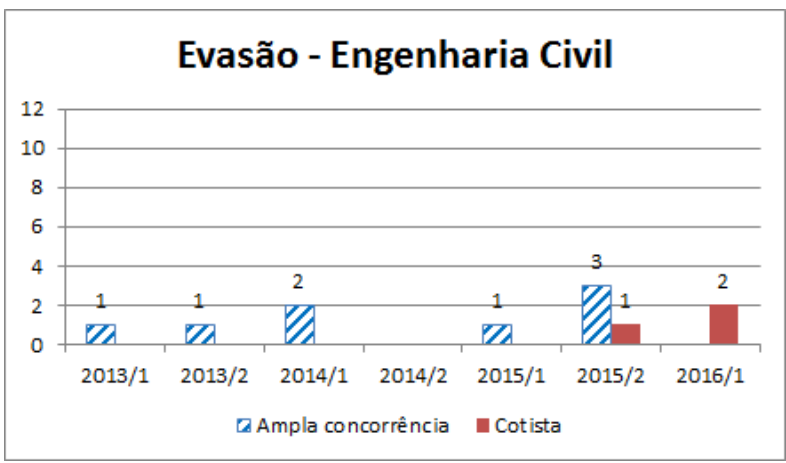

Gráfico 17 - Evasão por períodos -Direito

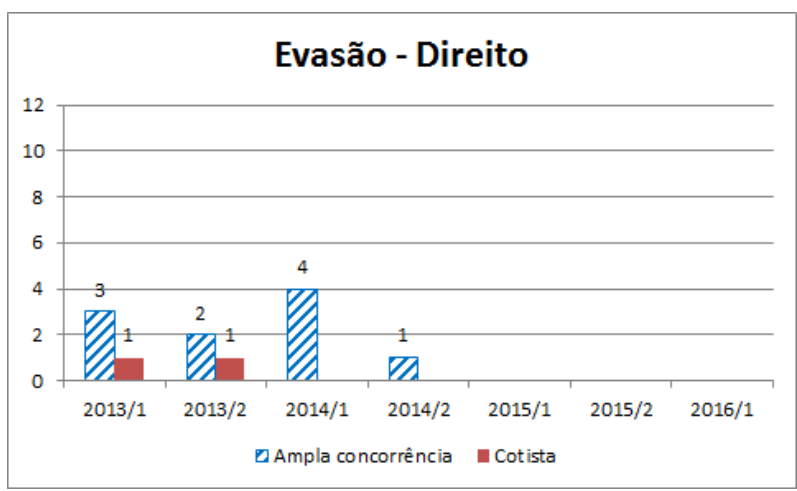

Fonte: Dados da UFOP (elaboração própria).
Gráfico 14 - Evasão por períodos - Nutrição

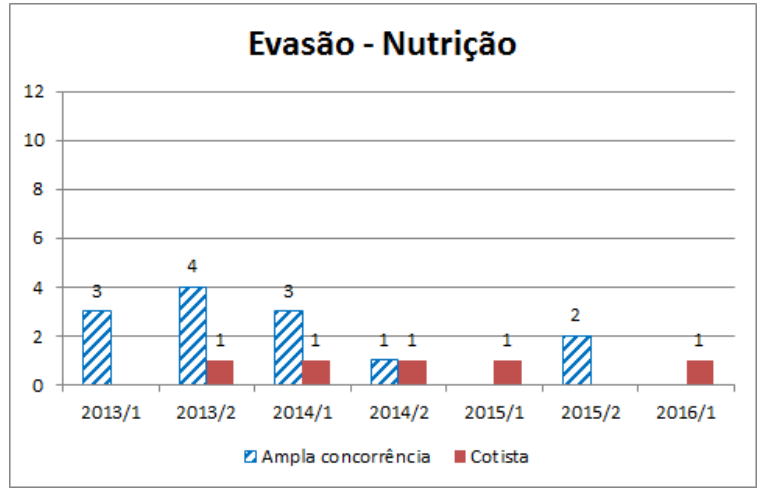

Gráfico 16 - Evasão por períodos - Engenharia de Computação

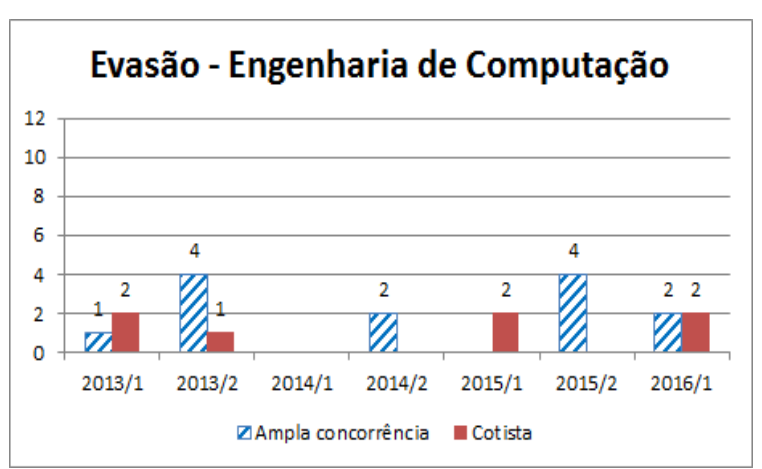

Gráfico18 - Evasão por períodos - Serviço Social

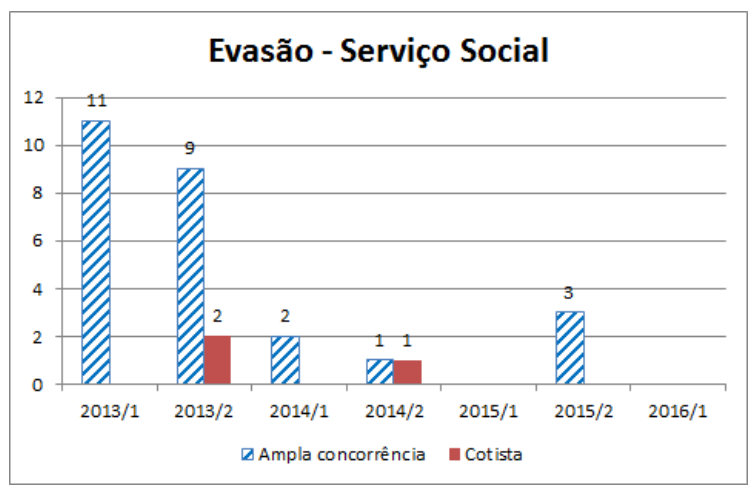




\subsection{Oportunidades acadêmicas}

A partir do Relatório de Gestão de Bolsas da UFOP 2013-2016, apresentamos o número de oportunidades acadêmicas, detalhando a participação dos estudantes nos programas da UFOP (Tabela 9).

Tabela 9 - Participação dos estudantes em programas/bolsas institucionais por modalidade de concorrência

\begin{tabular}{|c|c|c|c|c|c|c|c|c|c|c|c|c|c|}
\hline Curso & 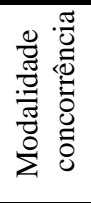 & $\begin{array}{l}\frac{\pi}{0} \\
\stackrel{8}{8} \\
\stackrel{8}{4}\end{array}$ & $\begin{array}{l}\text { 㺃 } \\
\text { 矛 } \\
\text { 离 }\end{array}$ & $\begin{array}{l}\frac{0}{0} \\
\frac{\pi}{0} \\
: 0 \\
0 \\
\Sigma\end{array}$ & $\begin{array}{l}\cdot \frac{\pi}{0} \\
.0 \\
\stackrel{0}{0} \\
\Sigma\end{array}$ & $\stackrel{5}{2}$ & $\frac{u}{\underline{a}}$ & $\underline{\underline{\theta}}$ & $\stackrel{\theta}{2}$ & $\sum_{2}^{U}$ & 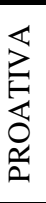 & $\begin{array}{l}\frac{\cup}{n} \\
0 \\
\frac{\infty}{2}\end{array}$ & 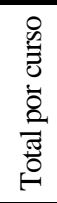 \\
\hline \multirow{2}{*}{ Medicina } & $\mathrm{AC}$ & 29 & 8 & 3 & 14 & 0 & 1 & 0 & 4 & 1 & 1 & 1 & 33 \\
\hline & PAA & 12 & 4 & 1 & 4 & 0 & 0 & 0 & 3 & 1 & 1 & 0 & 14 \\
\hline \multirow{2}{*}{ Nutrição } & $\mathrm{AC}$ & 25 & 3 & 0 & 3 & 1 & 1 & 0 & 0 & 1 & 3 & 0 & 12 \\
\hline & PAA & 9 & 1 & 0 & 2 & 0 & 0 & 0 & 1 & 0 & 0 & 0 & 4 \\
\hline \multirow{2}{*}{$\begin{array}{l}\text { Engenharia } \\
\text { Civil }\end{array}$} & $\mathrm{AC}$ & 25 & 1 & 1 & 2 & 0 & 1 & 1 & 2 & 0 & 0 & 0 & 8 \\
\hline & PAA & 11 & 1 & 1 & 2 & 0 & 0 & 0 & 0 & 0 & 0 & 1 & 5 \\
\hline \multirow{2}{*}{$\begin{array}{l}\text { Eng. de } \\
\text { Computaç } \\
\text { ão }\end{array}$} & $\mathrm{AC}$ & 22 & 0 & 3 & 3 & 0 & 0 & 0 & 0 & 0 & 0 & 0 & 6 \\
\hline & PAA & 10 & 0 & 1 & 1 & 0 & 1 & 0 & 0 & 0 & 0 & 0 & 3 \\
\hline \multirow{2}{*}{ Direito } & $\mathrm{AC}$ & 37 & 14 & 0 & 8 & 0 & 1 & 0 & 3 & 2 & 0 & 1 & 29 \\
\hline & PAA & 14 & 6 & 0 & 2 & 0 & 0 & 0 & 1 & 0 & 1 & 1 & 11 \\
\hline \multirow{2}{*}{$\begin{array}{l}\text { Serviço } \\
\text { Social }\end{array}$} & $\mathrm{AC}$ & 33 & 4 & 0 & 2 & 0 & 0 & 0 & 0 & 0 & 0 & 0 & 6 \\
\hline & PAA & 14 & 4 & 0 & 3 & 0 & 0 & 0 & 2 & 0 & 0 & 0 & 9 \\
\hline \multicolumn{2}{|c|}{$\begin{array}{c}\text { Total Ampla } \\
\text { concorrência (AC) }\end{array}$} & 171 & 30 & 7 & 32 & 1 & 4 & 1 & 9 & 4 & 4 & 2 & 94 \\
\hline \multicolumn{2}{|c|}{ Total Cotista (PAA) } & 70 & 16 & 3 & 14 & 0 & 1 & 0 & 7 & 1 & 2 & 2 & 46 \\
\hline \multicolumn{2}{|c|}{ Total geral } & 241 & 46 & 10 & 46 & 1 & 5 & 1 & 16 & 5 & 6 & 4 & 140 \\
\hline
\end{tabular}

Fonte: Dados da UFOP (elaboração própria). 
Os cursos de Medicina e de Direito possuem a maior participação de estudantes cotistas nos programas da UFOP (considerando as frequências absolutas). Foram 14 participações dos estudantes de Medicina e 11 dos estudantes de Direito. Somente no curso de Serviço Social a participação de estudantes cotistas em programas institucionais foi maior que a de estudantes da ampla concorrência. Isso é um dado importante, pois é esperada uma maior participação de estudantes da ampla concorrência, dado que o número de alunos que ingressaram nessa modalidade é superior.

Relevante observarmos que, na UFOP, o PIBIC prevê oportunidade a estudantes participantes da ação afirmativa, mas apenas um aluno dessa modalidade de concorrência participa do programa. A participação de estudantes beneficiados pela política de ação afirmativa nos programas de bolsas da UFOP é significativa, haja vista a distribuição de 46 bolsas para um total de 70 estudantes cotistas (isso corresponde a um atendimento de 65,7\% dos cotistas). Já na ampla concorrência, a porcentagem de alunos contemplados com bolsas é de 54,9\%. Ou seja, os dados indicam que há uma participação maior dos PAA nas oportunidades acadêmicas. Lembramos, no entanto, que essa relação entre o número de bolsas e o número de alunos é complexa, pois um mesmo aluno pode participar em mais de um programa e mais de uma vez. Portanto, as oportunidades devem ser analisadas com cautela.

O PET e o PIBITI não registraram a participação de estudantes cotistas. Extensão e Monitoria são os programas que mais contemplam a participação de estudantes cotistas e de ampla concorrência. Portanto, os programas de bolsas da UFOP, como indicadores de oportunidades acadêmicas, demonstram que há uma quantidade grande de cotistas participantes. Mas ainda falta uma distribuição mais equânime dos programas entre os cursos.

\section{Considerações finais}

Os processos de expansão e de democratização do Ensino Superior brasileiro, ocorridos a partir do início do século XXI, constituem um marco histórico para as universidades, principalmente no que diz respeito à composição do seu corpo discente, que passou a ser constituído por uma maior diversidade cultural, social e econômica. Nesse contexto, esta pesquisa teve por motivação conhecer o percurso universitário de alunos de camadas populares ingressantes 
no Ensino Superior pela Política de Ação Afirmativa regida pela Lei nº 12.711 nos cursos de graduação presenciais da UFOP; comparar o perfil acadêmico dos estudantes cotistas e da ampla concorrência e investigar oportunidades aproveitadas no percurso universitário pelos alunos.

Verificamos que a maioria dos estudantes cotistas, embora tenha um desempenho menor na pontuação do ENEM e, ao ingressar, apresente dificuldades escolares e de adaptação ao meio universitário, no decorrer do curso, tem desempenho acadêmico similar ao dos estudantes da ampla concorrência. Esse foi um dos achados mais relevantes da nossa pesquisa. Diversos resultados encontrados, de maneira geral, estão nesse mesmo sentido. Considerando a amostra como um todo: existe diferença estatisticamente significativa entre a pontuação média do ENEM dos cotistas e dos estudantes da ampla concorrência, sendo os últimos detentores das maiores notas; não existe diferença estatisticamente significativa entre os coeficientes gerais (desempenho acadêmico após o ingresso na Universidade) dos estudantes cotistas e de ampla concorrência; ao compararmos a reprovação e a proporção de evasão de estudantes cotistas e de ampla concorrência, não encontramos diferença estatisticamente significativa; indiferente da modalidade de ingresso, os maiores índices de reprovações em disciplinas e de evasão concentram-se nos períodos iniciais dos cursos; os programas de bolsas da UFOP, como indicadores de oportunidades acadêmicas, demonstram que há uma quantidade grande de cotistas participantes.

Quanto ao nível socioeconômico, tanto para a amostra como um todo, como para os cursos separadamente, existe uma diferença estatisticamente significativa entre o nível socioeconômico de alunos cotistas e de ampla concorrência, sendo maior o NSE de alunos de ampla concorrência. Segundo Rodrigues, Matos e Ferreira (2017), esse é um resultado empírico de que as políticas afirmativas estão desempenhando uma função esperada de inclusão social. Em relação à política de cotas na UFOP, podemos inferir que esta tem cumprido o seu papel social e contribuído para o acesso de uma parcela significativa de estudantes de camadas populares no Ensino Superior, sobretudo nos cursos de maior prestígio.

Como pesquisas futuras, sugerimos: 1) efetuar uma avaliação considerando o ciclo completo, ou seja, do ingresso à diplomação, incluindo os resultados do ENADE, visando avaliar todo o percurso acadêmico dos estudantes cotistas na Universidade; 2) aprofundar os estudos em relação à experiência universitária de acordo com o gênero, raça/cor e idade; 3 ) avaliar os principais impactos da Lei 12.711 na universidade, no que tange a assistência estudantil, moradia, utilização 
dos restaurantes e bibliotecas, investimentos didático-pedagógicos, dentre outros; 5) estudar as possíveis mudanças culturais e econômicas propiciadas pelo ensino superior aos estudantes de camadas populares e seus familiares.

Ainda há muito a ser feito para que a igualdade de oportunidades e a permanência desses estudantes no Ensino Superior sejam garantidas. Reiteramos que é necessário analisar as dificuldades enfrentadas pelos estudantes na educação superior, bem como identificar as reais necessidades materiais e didático-pedagógicas que garantam a permanência do estudante nesse nível de ensino.

\section{Referências}

ALVES, Maria Teresa Gonzaga; SOARES, José Francisco; XAVIER, Flavia Pereira. Índice socioeconômico das escolas de educação básica brasileiras. Ensaio: Avaliação e Políticas Públicas em Educação, Rio de Janeiro, v. 22, n. 84, p. 671-704, 2014. Disponível em: http://www.scielo.br/pdf/ensaio/v22n84/a05v22n84.pdf. Acesso em: 9 jul. 2018.

BRASIL. Lei $\mathbf{n}^{\mathbf{0}}$. 12.711, de 29 de agosto de 2012. Dispõe sobre o ingresso nas universidades federais e nas instituições federais de ensino técnico de nível médio e dá outras providências. Brasília, 2012.

COULLON, Alain. A condição de estudante: a entrada na vida universitária. Salvador: EDUFBA, 2008.

DOMINGUES, Petrônio. Ações Afirmativas para negros no Brasil: o início de uma reparação histórica. Revista Brasileira de Educação, Rio de Janeiro, n. 29, p. 164-176, maio/jun./jul./ago. 2005.

GARCIA, Francisco da Costa; JESUS, Girlene Ribeiro de. Uma avaliação do sistema de cotas raciais da Universidade de Brasília. Estudos em Avaliação Educacional, São Paulo, v. 26, n. 61, p. 146-165, jan./abr. 2015. Disponível em:

http://publicacoes.fcc.org.br/ojs/index.php/eae/article/view/2773. Acesso em: 9 jul. 2018.

INSTITUTO NACIONAL DE ESTUDOS E PESQUISAS EDUCACIONAIS ANÍSIO TEIXEIRA. Censo da educação superior 2013: resumo técnico. Brasília: INEP, 2015.

MUNANGA, Kabengele. Política de Ação Afirmativa no Brasil: consenso e desacordo na política de cotas na universidade pública. In: REPETTO, Maxim; NEVES, Leandro Roberto; FERNANDES, Maria Luiza (org.). Universidade inconclusa: os desafios da desigualdade. Boa Vista: Ed. da UFRR, 2008. p. 35-88. 
PAIVA, Angela Randolpho; ALMEIDA, Lady Christina. Mudança no campus: falam os gestores das universidades com ações afirmativas. In: PAIVA, Angela Randolpho (org.). Entre dados e fatos: ação afirmativa nas universidades públicas brasileiras. Rio de Janeiro: PUC-Rio, Pallas, 2010. p. 75-116.

PORTES, Écio Antônio; SILVA, Cibelle Cristina Lopes. Os efeitos do capital cultural na distribuição dos privilégios universitários: o caso dos bolsistas de iniciação científica da UFSJ. Tempos e Espaços, Aracaju, v. 6, p. 57-62, 2011.

PRATES, Antonio Augusto Pereira. Desigualdade e expansão do ensino superior na sociedade contemporânea: o caso brasileiro do final do século XX ao princípio do século XXI. Belo Horizonte: Fino Traço, 2014.

RODRIGUES, Erica Castilho; MATOS, Daniel Abud Seabra; FERREIRA, Aline dos Santos. Nível socioeconômico e ensino superior: cálculo e aplicações. Avaliação, Campinas, SP, v. 22, n. 2, p. 494-511, jul. 2017. Disponível em: http://www.scielo.br/scielo.php?pid=S141440772017000200494\&script=sci_abstract\&tlng=pt. Acesso em: 9 jul. 2018.

SANTOS, Adilson Pereira dos. Política de ação afirmativa, novo ingrediente na luta pela democratização do Ensino Superior: a experiência da Universidade Federal de Ouro Preto. 2011. Dissertação (Mestrado) - Universidade Federal do Rio de Janeiro, Rio de Janeiro, 2011.

SILVA FILHO, Penildon. Políticas de ação afirmativa na educação brasileira: estudo de caso do programa de reserva de vagas para ingresso na Universidade Federal da Bahia. Jundiaí: Paco Editorial, 2013.

SOUSA, Letícia Pereira de. Reserva de vagas na Universidade Federal de São João del-Rei: o perfil dos beneficiados pela Ação Afirmativa 2 em 2010. 2013. 240 f. Dissertação (Mestrado em Educação) - Programa de Pós-graduação em Processos Educativos e Práticas Escolares, Universidade Federal de São João Del-Rei, São João Del-Rei, 2013.

SOUZA, Iael de. Estudo, estudar, ser estudante no Ensino Superior: condições gerais imanentes e contexto socioeconômico cultural das classes populares. Revista Labor, Fortaleza, v. 1, n. 16, p. 112-136, 2016. Disponível em: http://www.periodicos.ufc.br/labor/article/view/6515. Acesso em: 9 jul. 2018. 